\title{
The Boundary States Investigation of the Proportional Loaded Materials Using the Multiaxial Strength Criteria
}

Jan Fuxa (CZ) jan.fuxa@vsb.cz

František Fojtík (CZ) frantisek.fojtik@vsb.cz

\section{BIOGRAPHICAL NOTES}

prof. Ing. Jan Fuxa, CSc. (born 1947) is employed on 60\% part-time as research-pedagogical senior lecturer on the department of Mechanics of Materials at VŠB - TU Ostrava, which has headed until retirement. After the graduation in 1970 on Faculty of Mechanical Engineering VŠB-TU Ostrava professor Fuxa worked as an engineer and computational engineer in ŽĎAS (Machine works and Foundries in Ždár nad Sázavou), in VÚHŽ (Research institute of iron metallurgy in Dobrá near Frýdek-Místek), where has according to his projects and patents built laboratory of plasticity. Since 1986 he works on VŠB-TU Ostrava, where has been in 1991 habilitated as docent with research work "Stress state of conveyor belt cylinders". In 2001 he has been appointed as professor. Professor Fuxa had participated on establishment of study course "Applied mechanics" for which has instituted two subjects - Theory of plasticity and Creep and thermal loading. He has also actively participated on building of cathedral laboratories, especially designs of test devices and methodics of material testing by multi-axial static and fatigue loading. Professor Fuxa has been the head of Academic senate of Faculty of Mechanical Engineering VŠB-TU Ostrava over two innings. After retirement he actively applies oneself to fine art, especially graphics, photo-graphics and oil painting. Additional informations are mentioned on page 152 in encyclopedia "Who I who personalities of Czech present - 5000 biographies", 5. publication, 2005, Micheal Třeštík - editorial, ISBN 80-902586-9-7.

Ing. František Fojtík, Ph.D (born 1978) is a Deputy Head on the department of Mechanics of Materials at VŠB - TU Ostrava, Faculty of Mechanical Engineering. Ing. Fojtík graduated at VŠB - TU Ostrava, Faculty of Mechanical Engineering in 2002, in the branch of applied mechanics. Afterwards, he started to study a Ph.D. course in branch of applied mechanics and graduated in 2007. At the same time, he has worked as research and scientific staff member at VŠB - TU Ostrava, Faculty of Mechanical Engineering, department of Mechanics of Materials. Since 2005 he has worked as an assistant professor at VŠB - TU Ostrava, Faculty of Mechanical Engineering, department of Mechanics of Materials. His professional specialization is especially computational prediction and experimental verification of multiaxial fatigue analysis of materials as well as experimental stress analysis in the field of elastic and plastic deformations by means of strain gage method and finite element method. He also specializes on measurements of residual stresses, design of force and torque transducers. He is an author 
and coauthor of many industrial and functional designs and other 40 conference publications and periodical papers.

\section{KEY WORDS}

Experiment in Multiaxial Fatigue, Combined Loading, High-Cycle Fatigue, Multiaxial Analysis

\section{ABSTRACT}

The contribution describes the experimental results obtained from the combined loading of the specimens in the field of high-cycle fatigue. Those specimens were manufactured from common construction steel 11523 .

The following experiments were performed: The first set of the specimen was loaded by the alternating torque amplitude. The second set was loaded by the alternating amplitude of the bending moment. The next set was loading by alternating amplitude of the torque and bending moment. This experiment was performed for two loading levels applied in the same phase. The results were evaluated by the conjugated strength criterion and another generally used multiaxial fatigue criteria. The stress-strain analysis of the specimens by FEM was performed to determine parameters (constants) of particular strength criteria.

\section{INTRODUCTION}

Although the material failure phenomenon in the conditions of multiaxial fatigue is investigated for many years by world-known research institutes, the reliable mathematical description making possible to describe this boundary state was not introduced yet. Hence, it is still necessary to perform expensive prototype verification [1]. The evidence of this fact is number of laboratories especially in aircraft and automotive industry. We bring another build-stone into the mosaic of this interesting technical field in this contribution.

Number of fatigue experiments using both the reconstructed and new proposed devices [2], were performed at the Department of Mechanics of Matierial, VSB-TU Ostrava. The aim was to verify the ability of the conjugated strength criterion [3] proposed at our department and to use it for coupling of static and fatigue [4] multiaxial strength criterion.

Our contribution describes certain findings obtained from four different types of mechanical ma- terial loading. The experimental data obtained at the fatigue limit were judged primarily, i.e. for specimens which were not damaged after $10^{7}$ cycles. The bellow presented methodology is made for this lifetime. Those experiments were performed under co-phase loading with the testing frequency of $25 \mathrm{~Hz}$. The loading amplitude (soft cycle) with sinus shape was controlled in the experiments. The obtained data were used to determine the constants of conjugated strength criterion whose application can be suitable even for prediction of boundary cycle number in the field of lifetime strength.

\section{Experimental Material}

The experiments were performed on the hollow specimens (Fig. 1) manufactured from low carbon steel CSN 411523.1 melting T31052. Those specimens were polished on the outer diameter. The chemical content and basic mechanical properties of this material are summarized in Tab. 1 and Tab. 2.

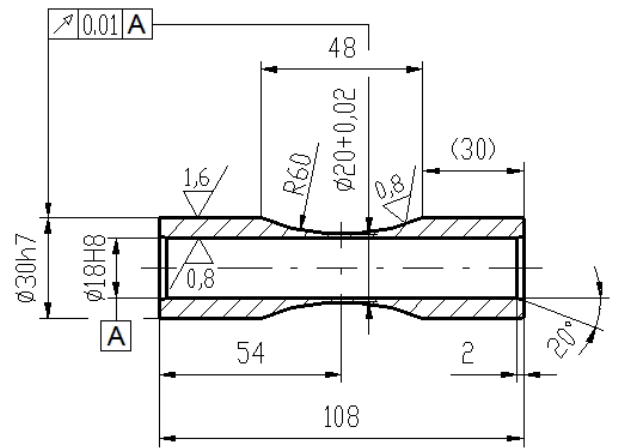

Fig. 1 Testing specimen

\begin{tabular}{|c|c|c|c|c|c|}
\hline $\mathbf{C} \%$ & $\mathbf{M n} \%$ & $\mathbf{S i} \%$ & $\mathbf{P} \%$ & $\mathbf{S} \%$ & $\mathbf{C u} \%$ \\
\hline 0,18 & 1,38 & 0,4 & 0,018 & 0,006 & 0,05 \\
\hline
\end{tabular}

Tab. 1 Chemical properties of the specimen material

\begin{tabular}{|c|c|c|c|}
\hline $\begin{array}{c}\text { Ultimate } \\
\text { tensile } \\
\text { strength } \\
\text { [MPa] }\end{array}$ & $\begin{array}{c}\text { Tensile yield } \\
\text { stress } \\
\text { [MPa] }\end{array}$ & $\begin{array}{c}\text { Elongation } \\
\text { at fracture } \\
\text { [\%] }\end{array}$ & $\begin{array}{c}\text { Reduction } \\
\text { of area at } \\
\text { fracture } \\
\text { [\%] }\end{array}$ \\
\hline 560 & 400 & 31,1 & 74,0 \\
\hline
\end{tabular}

Tab. 2 Mechanical properties of specimen material

The following material parameters were experimentally found out for the setting of bellow mentioned fatigue criteria.

- tensile modulus: $\mathrm{E}=2,06.10^{5} \mathrm{MPa}$, 
- Poisson's ratio: $\mu=0,3$.

Other material parameters determined via experiment for given material and melting which are necessary for setting of given fatigue criteria:

fatigue limit in fully reversed torsion:

$$
\mathrm{t}_{-1}=149,1 \mathrm{MPa} \text {, }
$$

- fatigue limit in fully reversed plane bending:

$$
\mathrm{f}_{-1}=311 \mathrm{MPa} \text {, }
$$

- fatigue limit in repeated bending: $\mathrm{f}_{0}=380 \mathrm{MPa}$, - tensile true fracure strength: $\sigma_{\mathrm{f}}=979,2 \mathrm{MPa}$, ntorsion true fracure strength: $\tau_{\mathrm{f}}=516,6 \mathrm{MPa}$.

\section{Used Multiaxial Fatigue Methods}

The following generally used fatigue strength criteria were used for the analysis of performed experiments. The results obtained in experimental way for given loading combination on the fatigue limit will be judged by those criteria.

\section{Crossland Method}

Crossland published his results in the $50^{\text {th }}$ of previous century. His criterion uses the square root from the second invariant of stress tensor. This invariant is determined from the stress amplitude. Another term added to the equation is the hydrostatic stress calculated from maximal stress values [5].

$a_{C} \cdot\left(\sqrt{J_{2}}\right)_{a}+b_{C} \cdot \sigma_{H, \max } \leq f_{-1}$

where coefficients $a_{c}$ and $b_{c}$ are defined as:

$a_{C}=\frac{f_{-1}}{t_{-1}}$

$b_{C}=\left(3-\frac{f_{-1}}{t_{-1}}\right)$

other parameters in the equation are:

$\mathrm{J}_{2}$ second invariant of stress tensor deviator, $\mathrm{f}_{-1} \mathrm{fa}-$ tigue limit in fully reversed axial loading (in tension, in bending or in rotating bending), $\sigma_{\mathrm{H}, \max }$ maximum value of hydrostatic stress during load history, $\mathrm{t}_{-1}$ fatigue limit in fully reversed torsion.

\section{Sines Method}

Sines published his results in the same period as Crossland. The formulation of both criteria as similar, they differ in the determination of hydrostatic stress. Sines calculate this stress from mean stress values [6].

$a_{S} \cdot\left(\sqrt{J_{2}}\right)_{a}+b_{S} \cdot \sigma_{H, m} \leq f_{-1}$ where coefficients $\mathrm{a}_{\mathrm{s}}$ and $\mathrm{b}_{\mathrm{s}}$ are defined as:

$$
\begin{aligned}
& a_{S}=\frac{f_{-1}}{t_{-1}} \\
& b_{S}=6 \cdot \frac{f_{-1}}{f_{0}}-\sqrt{3} \cdot \frac{f_{-1}}{t_{-1}}
\end{aligned}
$$

where $\mathrm{f}_{0}$ is fatigue limit in repeated bending $\sigma_{\mathrm{H}, \mathrm{m}}$ mean value of hydrostatic stress during load history, other parameters in the equation are defined as in the case of Crossland Method.

\section{McDiarmid Method}

This criterion is widely used. On the base of number of experiments McDiarmid proposed the following shape of the criterion:

$$
\frac{f_{-1}}{t_{A B}} \cdot C_{a}+\frac{f_{-1}}{2 \cdot S_{u}} \cdot N_{\max } \leq f_{-1}
$$

where $\mathrm{C}_{\mathrm{a}}$ is shear stress amplitude on an examined plane, $\mathrm{f}_{-1}$ is fatigue limit in fully reversed axial loading, $\mathrm{N}_{\max }$ is maximum normal stress on the plane examined, $S_{u}$ is tensile strength, $t_{A B}$ is fatigue limit in fully reversed torsion with crack in A or B system. The crack parallel with the surface is typical for the type A. The crack leading inside down from the surface is typical for type B [7].

\section{Papadopoulos Method}

The Papadopoulos method is based on the Dang Van Criterion. However this method integrates the input variables in all planes. The method can be found in following shape [8].

$$
\sqrt{a_{p} \cdot\left(T_{a}^{2}\right)}+b_{p} \cdot \sigma_{H, \max } \leq f_{-1}
$$

where:

$$
\begin{aligned}
& a_{p}=5 \cdot \kappa^{2} \\
& b_{p}=3-\sqrt{3} \cdot \kappa \\
& \kappa=\frac{f_{-1}}{t_{-1}}
\end{aligned}
$$

\section{Papuga PCr Method}

Papuga proposed the criterion on the base of long-term studies of multiaxial fatigue criteria in following shape (7) [9]. According to his research embodies this criterion the most accurate results 
for wide range of materials.

$$
\sqrt{a_{C} \cdot C_{a}^{2}}+b_{C} \cdot N_{a}+\frac{t_{-1}}{f_{0}} \cdot N_{a} \leq f_{-1}
$$

It is valid for following ratio of fatigue limits:

$$
\begin{aligned}
& \kappa<\sqrt{\frac{4}{3}} \cong 1.155 \\
& a_{C}=\frac{\kappa^{2}}{2}+\frac{\sqrt{\kappa^{4}-\kappa^{2}}}{2}, b_{C}=f_{n} \\
& \kappa \geq \sqrt{\frac{4}{3}} \cong 1.155 \\
& a_{C}=\left(\frac{4 \cdot \kappa^{2}}{4+\kappa^{2}}\right), b_{C}=\frac{8 \cdot f_{-1} \cdot \kappa^{2} \cdot\left(4-\kappa^{2}\right)}{\left(4+\kappa^{2}\right)^{2}}
\end{aligned}
$$

All mentioned criteria according to the results from $(1,3,5,6,7)$ judge if the component is able to transfer the infinity of loading cycles. To judge of those criteria the fatigue index error $\Delta F I$ is used. It shows the rate of deviation from the ideal equilibrium of the left and right hand sides of mentioned criterion relations [10].

$$
\Delta F I=\frac{\operatorname{LHS}(\text { load })-f_{-1}}{f_{-1}} \cdot 100 \%
$$

where LHS is the left hand side of the equation. The relation $\mathrm{LHS}(\mathrm{load}) \leq \mathrm{f}_{-1}$ has to be fulfilled. If LHS is greater, the component can fail.

\section{Conjugates Strength Criterion}

This criterion was proposed by Fuxa [3]. For the crack initiation in $\mathrm{N}$-th cycle it can be written in following shape:

$$
S_{\sigma}=A_{N}-B_{N} \cdot \sigma_{R}
$$

where $\mathrm{S}_{\sigma}$ marks the stress intensity and is defined as:

$$
S_{\sigma}=\frac{1}{\sqrt{2}} \cdot \sqrt{\left[\begin{array}{l}
\left(\sigma_{1}-\sigma_{2}\right)^{2}+\left(\sigma_{2}-\sigma_{3}\right)^{2} \\
+\left(\sigma_{3}-\sigma_{1}\right)^{2}
\end{array}\right]}
$$

$\sigma_{\mathrm{R}}$ is the reference stress value producing the iden- tical value as the octaedric normal stress and can be written as:

$\sigma_{R}=\left(\sigma_{1}+\sigma_{2}+\sigma_{3}\right) / 3$

where $\sigma_{1}, \sigma_{2}, \sigma_{3}$ are the principal stresses. The value $A_{N}$ can be considered as dependent on the cycle number $\mathrm{N}$ and is written as:

$$
\begin{aligned}
& A_{N}=\left(A_{O}+A_{C}\right) / 2+\left(A_{O}-A_{C}\right) / 2 . \\
& \cos \left(\pi \cdot\left(\log N / \log N_{C}\right)^{a}\right) \ldots N<1, N_{C}>
\end{aligned}
$$

$A_{o}$ is the constant of the static reference strength criterion and can be determined based on the torsion test:

$$
A_{O}=3^{1 / 2} \cdot \tau_{f}
$$

$A_{C}$ the stress intensity at the fatigue limit in torsion, $N_{C}$ number of cycles at the fatigue limit, $\alpha$ material constant, $B_{N}$ is the constant equal to:

$$
B_{N}=3 \cdot\left(\sqrt{3} \cdot \tau_{f} / \sigma_{f}-1\right)
$$

where $\sigma_{\mathrm{f}}$ is the value of true fracure strength in tension and $\tau_{\mathrm{f}}$ is the value of true fracure strength in torsion.

The absolute value of mean relative error of the used approximation can be determined as follows:

$C H_{F}=A B S\left(S_{\sigma i}-S_{\sigma F i}\right) / S_{\sigma i} \cdot 100 \%$

where $S_{\sigma \mathrm{i}}$ are the calculated values of the stress intensities stated in the appropriate table and $S_{\sigma \mathrm{Fi}}$ are the calculated values according to the Fuxa's approximation.

\section{First Experiment - Alternating Torsion}

The first set of specimens was loaded by the nominal amplitude of the torque. In the case of first specimen the proper amplitude was set and the number of cycles until failure was registered. In case of other specimens was this amplitude stepwise reduced until the fatigue limit - $10^{7}$ cycles was reached. The experiments were performed at the frequency $25 \mathrm{~Hz}$. The experimental results are summarized in Tab. 3 where $\sigma_{\mathrm{a}}$ is the stress amplitude in bending and $\tau_{\mathrm{a}}$ is the stress amplitude in torsion. The result stress was obtained via stress/ 
strain analysis using FEM in the software ANSYS. The limit stress intensity in $\mathrm{N}_{\mathrm{f}}$ cycles is depicted in Fig. 2. It is calculated from obtained stress values.

\begin{tabular}{|c|c|c|c|c|}
\hline Nr. & $\begin{array}{c}\boldsymbol{\sigma}_{\mathbf{a}} \\
{[\mathrm{MPa}]}\end{array}$ & $\begin{array}{c}\tau_{\mathrm{a}} \\
{[\mathrm{MPa}]}\end{array}$ & \multicolumn{1}{c|}{$\begin{array}{c}\mathbf{N}_{\mathbf{f}} \\
\text { [-] }\end{array}$} & Notes \\
\hline $\mathbf{1}$ & 0 & 181,0 & 92200 & \\
\hline $\mathbf{2}$ & 0 & 162,7 & 351800 & \\
\hline $\mathbf{3}$ & 0 & 156,2 & 749450 & \\
\hline $\mathbf{4}$ & 0 & 151,4 & 1944600 & \\
\hline $\mathbf{5}$ & 0 & 149,1 & 11001000 & $\begin{array}{c}\text { No crack } \\
\text { generated }\end{array}$ \\
\hline
\end{tabular}

Tab. 3 Experimental results for alternating torsion

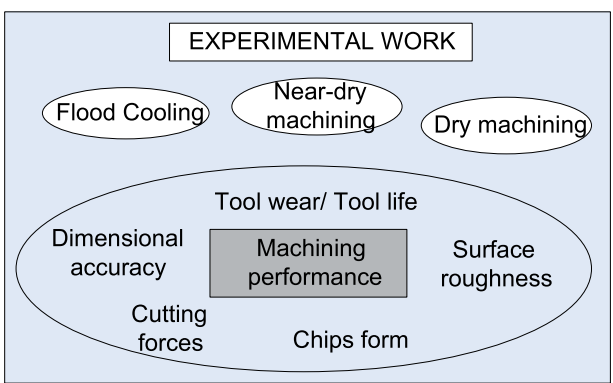

Fig. 2 S-N curve for alternating torsion

\section{Second Experiment - Alternating Bending}

The second set of specimens was loaded by the nominal amplitude of the bending moment. In the case of first specimen the proper amplitude was set and the number of cycles until failure was registered. In case of other specimens was this amplitude stepwise reduced until the fatigue limit $-10^{7}$ cycles - was reached. The experiments were performed at the frequency $25 \mathrm{~Hz}$ again. The experimental results are summarized in Tab. 4 where $\sigma_{\text {a }}$ is the stress amplitude in bending and $\tau_{\mathrm{a}}$ is the stress amplitude in torsion.

The result stress was obtained via stress/strain analysis using FEM in the software ANSYS. The limit stress intensity leading to the crack initiation in $\mathrm{N}_{\mathrm{f}}$ cycles is depicted in Fig. 3. It is calculated from obtained stress values. The data are approximated according to (9).

\section{Third Experiment - Alternating Bending and Torsion}

The third set of specimens was loaded by the nominal amplitude of the bending moment and nominal amplitude of the torque. The loading was

\begin{tabular}{|c|c|c|c|c|}
\hline Nr. & $\begin{array}{c}\mathbf{\sigma}_{\mathbf{a}} \\
{[\mathrm{MPa}]}\end{array}$ & $\begin{array}{c}\tau_{\mathrm{a}} \\
{[\mathrm{MPa}]}\end{array}$ & \multicolumn{1}{c|}{$\begin{array}{c}\mathbf{N}_{\mathbf{f}} \\
\text { [-] }\end{array}$} & Notes \\
\hline $\mathbf{1}$ & 376,9 & 0 & 89700 & \\
\hline $\mathbf{2}$ & 352,4 & 0 & 196635 & \\
\hline $\mathbf{3}$ & 336,8 & 0 & 214430 & \\
\hline $\mathbf{4}$ & 324,8 & 0 & 1262300 & \\
\hline $\mathbf{5}$ & 319,0 & 0 & 5037000 & \\
\hline $\mathbf{6}$ & 311,0 & 0 & 11631000 & $\begin{array}{c}\text { No crack } \\
\text { generated }\end{array}$ \\
\hline
\end{tabular}

Tab. 4 Experimental results for alternating bending

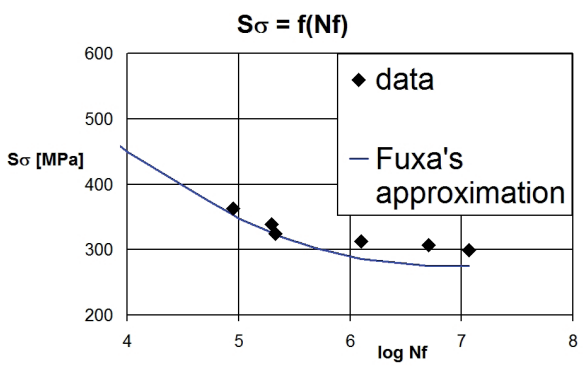

Fig. 3 S-N curve for alternating bending

performed with zero phase shifts. The experiments were performed at the frequency $25 \mathrm{~Hz}$ again. The process was the same as in previous cases. The experimental results are summarized in Tab. 5. The limit stress intensity leading to the crack initiation in $\mathrm{N}_{\mathrm{f}}$ cycles is depicted in Fig. 4.

\section{Fourth Experiment - Alternating Bending and Torsion}

The fourth set of specimens was loaded by the nominal amplitude of the bending moment and nominal amplitude of the torque. The different ratio of both amplitudes than in previous case was chosen. The process was the same as in previous cases. The experimental results are summarized in Tab. 6. The limit stress intensity leading to the crack initiation in $\mathrm{N}_{f}$ cycles is depicted in Fig. 5. It is determined from measured values which were transformed into the stress state in the critical spot of the specimen.

\section{Experimental Results Analysis}

The obtained experimental results from all described experiments were used for the analysis of above mentioned fatigue stress criterions. The software Pragtic [10] was used for the analysis. It 
contains all mentioned criteria with the exception of Conjugated stress criterion which was proposed at the authors' laboratory. The program in Micro-

\begin{tabular}{|c|c|c|c|c|}
\hline $\mathbf{N r}$ & $\begin{array}{c}\mathbf{\sigma}_{\mathbf{a}} \\
{[\mathrm{MPa}]}\end{array}$ & $\begin{array}{c}\tau_{\mathrm{a}} \\
{[\mathrm{MPa}]}\end{array}$ & \multicolumn{1}{c|}{$\begin{array}{c}\mathbf{N}_{\mathbf{f}} \\
{[-]}\end{array}$} & Notes \\
\hline $\mathbf{1}$ & 224,3 & 150,4 & 56100 & \\
\hline $\mathbf{2}$ & 203,5 & 136,5 & 290400 & \\
\hline $\mathbf{3}$ & 199,6 & 133,9 & 821400 & \\
\hline $\mathbf{4}$ & 189,7 & 127,2 & 1069800 & \\
\hline $\mathbf{5}$ & 184,2 & 123,5 & 4005000 & \\
\hline $\mathbf{6}$ & 175,6 & 117,7 & 10146000 & $\begin{array}{c}\text { No crack } \\
\text { generated }\end{array}$ \\
\hline
\end{tabular}

Tab. 5 Experimental results for alternating torsion and alternating bending

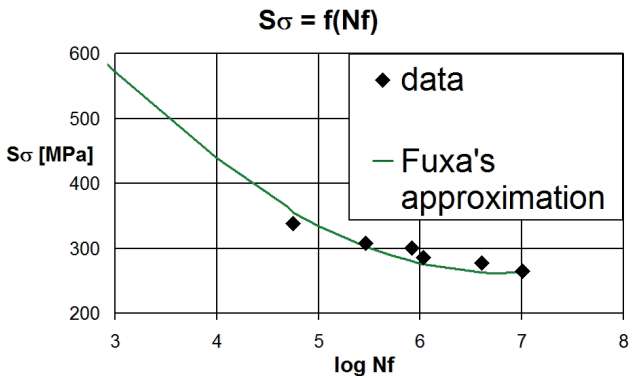

Fig. 4 S-N curve for alternating torsion and alternating bending soft Office Excel was created for the analysis of this criterion. The results of this study are depicted in Tab. 7.

\begin{tabular}{|c|c|c|c|c|} 
Nr. & $\begin{array}{c}\boldsymbol{\sigma}_{\mathbf{a}} \\
{[\mathrm{MPa}]}\end{array}$ & \multicolumn{1}{c}{$\tau_{\mathrm{a}}$} & \multicolumn{1}{c|}{$\mathbf{N}_{\mathbf{f}}$} & Notes \\
\hline $\mathbf{1}$ & 341,7 & 76,4 & 33100 & \\
\hline $\mathbf{2}$ & 321,0 & 71,7 & 108600 & \\
\hline $\mathbf{3}$ & 318,0 & 71,1 & 114900 & \\
\hline $\mathbf{4}$ & 293,4 & 65,6 & 657500 & \\
\hline $\mathbf{5}$ & 175,6 & 117,7 & 2827300 & \\
\hline $\mathbf{6}$ & 269,5 & 60,3 & 11819000 & $\begin{array}{c}\text { No crack } \\
\text { generated }\end{array}$ \\
\hline
\end{tabular}

Tab. 6 Experimental results for alternating torsion and alternating bending

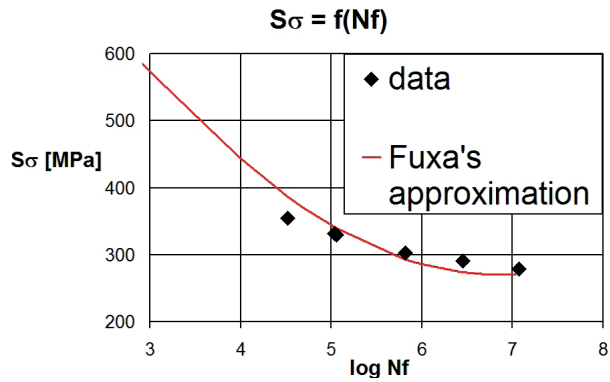

Fig. 5 S-N curve for alternating torsion and alternating bending

\begin{tabular}{|c|c|c|c|c|c|c|c|c|}
\hline \multirow[b]{2}{*}{ Nr. } & \multirow[b]{2}{*}{$\begin{array}{c}\sigma_{\mathrm{a}} \\
{[\mathrm{MPa}]}\end{array}$} & \multirow[b]{2}{*}{$\begin{array}{c}\tau_{\mathrm{a}} \\
{[\mathrm{MPa}]}\end{array}$} & \multicolumn{6}{|c|}{$\Delta \mathrm{FI}(\%), \mathrm{CH}_{\mathrm{F}}(\%)$} \\
\hline & & & Crossland & Sines & McDiarmid & $\begin{array}{l}\text { Papado- } \\
\text { pouos }\end{array}$ & Papuga PCr & Fuxa \\
\hline 1 & 0 & 149,1 & 0,0 & 0,0 & 0,0 & 0,0 & 0,0 & 0,15 \\
\hline 2 & 311,0 & 0 & 0,0 & 20,5 & 18,2 & 0,0 & 0,0 & 7,9 \\
\hline 3 & 318,0 & 71,1 & $-7,3$ & 4,3 & $-11,0$ & $-7,3$ & $-4,4$ & 1,1 \\
\hline 4 & 269,5 & 60,3 & $-5,8$ & 12,0 & 6,9 & $-5,8$ & 5,0 & 2,7 \\
\hline
\end{tabular}

Tab. 7 Experimental results analysis

\section{Conclusion}

The often used multiaxial fatigue criteria of the authors Crosland [5], Sines [6], McDiarmid [7], Papadopoulos [8], Papuga [9] and the conjugated strength criterion [3] proposed by the authors of this contribution with the aim to couple static and fatigue multiaxial criterion were described. This approach enables the prediction of the fatigue crack initiation even in the field of lifetime strength.

The four sets of experiments on hollow, thin- walled specimens manufactured from the steel 11523.1 according to the CSN were proposed and performed at the laboratory of the Department of mechanics of materials, VSB - TU Ostrava for the verification of the mentioned criteria. The different stress states were generated in the specimens during the loading - torsion, bending, torsion and bending at different ratios of shear and normal stress. The stress states in the critical spot were determined from the measured data using FEM. 
The good prediction ability of the developed conjugated strength criterion is obvious from the summarizing Tab. 7.

\section{Acknowledgement}

The paper was created under support of GACR, project no: 101/08/P141.

\section{References}

[1] Trebuňa, F., Šimčák, F. (2004). Odolnost' prvkov mechanických sústav. Emilena, Košice

[2] Fuxa, J., Fojtík, F., Kubala, R. (2007). Torque machine fit for high cycle fatigue of material testing. Experimental Stress Analysis, Hotel Výhledy

[3] Fuxa, J., Kubala, R., Fojtík F. (2006). Idea of Conjugated Strength Criterion. Acta Mechanica Slovaca, vol. 1, pp. 125-130

[4] Fuxa, J., Poruba, Z., Fojtik, F. (2006). Conjugated Stress Criterion. New Method of Damage and Failure Analysis of Structural Parts, Ostrava, pp. 245-258

[5] Crossland, B. (1956). Effect of large hydrostatic pressure on the torsional fatigue strength of an alloy steel. Proc. Int. Conf. on Fatigue of Metals, Institution of Mechanical Engineers, London, pp. 138-149

[6] Sines, G. (1959). Behavior of metals under complex static and alternating stresses. Metal Fatigue. Red. G. Sines a J.L. Waisman, New York, McGraw Hill, pp. 145-469

[7] McDiarmid, D.L. (1991). A general criterion for high cycle multiaxial fatigue failure. Fatigue Fract. Engng. Mater. Struct., vol. 14, no. 4, pp. 429-453

[8] Papadopoulos, I.V., Davoli, P., Gorla C., Filippini M., Bernasconi A. (1997). A comparative study of multiaxial high-cycle fatigue criteria for metals. Int. J. Fatigue, vol. 19, no. 3, pp. 219-235

[9] Papuga, J., Růžička, M. (2008). Two new multiaxial criteria for high cycle fatigue computation. Int. J. Fatigue, vol. 30, no. 1, pp. 58-66

[10] Papuga, J. (2008). Program PragTic in research, engineering practice and competitive environment. Kunovice, Evektor, s.r.o., http://www. pragtic.com/docu/PragTicA_Intro.pdf

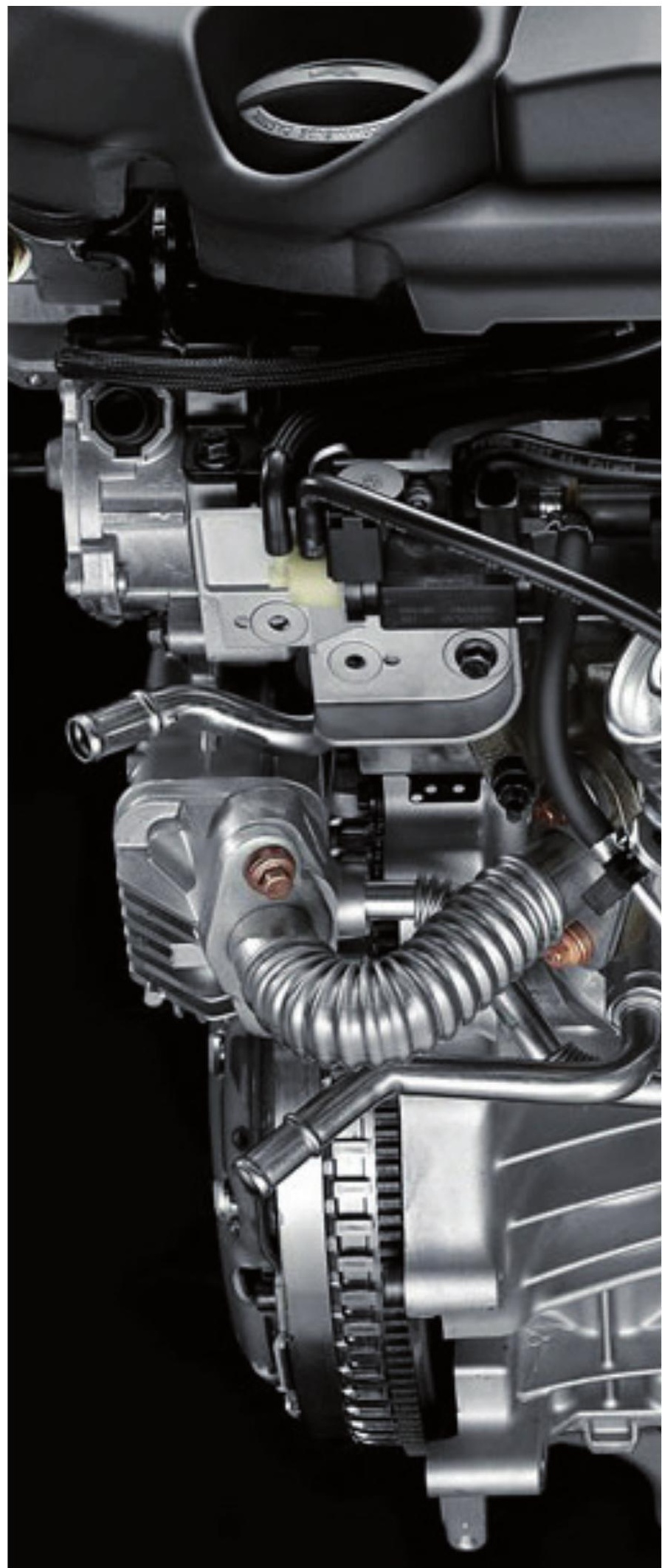

